\title{
Descriptive epidemiology: prevalence, incidence, sociodemographic factors, socioeconomic domains, and quality of life of epilepsy: an update and systematic review
}

\author{
Seyed Shahabeddin Sadr ${ }^{1}$, Javad Javanbakht ${ }^{1,2}$, Abbas Norouzi Javidan², Majid Ghaffarpour ${ }^{3}$, \\ Safoura Khamse ${ }^{1}$, Zeinab Naghshband ${ }^{1}$
}

\begin{abstract}
${ }^{1}$ Electrophysiology Research Center, Neuroscience Institute, Tehran University of Medical Sciences, Tehran, Iran

${ }^{2}$ Brain and Spinal Cord Injury Research Center, Neuroscience Institute, Tehran University of Medical Sciences, Tehran, Iran

${ }^{3}$ Iranian Center of Neurological Research, Neurology Department, Imam Khomeini Hospital, Tehran University of Medical Sciences, Tehran, Iran
\end{abstract}

Submitted: 3 April 2016

Accepted: 30 April 2016

Arch Med Sci 2018; 14, 4: 717-724

DOI: https://doi.org/10.5114/aoms.2016.60377

Copyright () 2016 Termedia \& Banach

\begin{abstract}
Introduction: The purpose of this study was to investigate the contributions of quality of life (QOL), sociodemographic factors (age, sex, etc.), residential areas, general attitudes toward epilepsy, socioeconomic domains, prevalence and incidence in epileptic patients from Iran.

Material and methods: A systematic literature search was conducted, including database searches in PubMed, Medline, Embase, ScienceDirect, Scopus, ISC, Health, Web of Science, and the Cochrane Library Database of relevant articles, personal files and systematic reviews to identify studies examining risk factors in epilepsy.

Results: This review article shows that certain socio-demographic and socio-economic factors, geographic variation in epidemiologic patterns of epilepsy as well as clinical factors may be crucial in determining QOL in epilepsy patients and provides further evidence supporting the validity of the scale in QOL based on consideration of different target groups in different areas. Conclusions: Prevalence of epilepsy appears to be correlated with socioeconomic status in the lower socioeconomic groups. Also demographic characteristics, socio-economic factors and clinical presentation are linked to different QOL of these patients among nations. The educational program has a beneficial effect on self-management behaviors in patients with epilepsy. More work needs to be done to improve tools that help to evaluate efficiently the health-related quality of life of people with epilepsy.
\end{abstract}

Key words: epilepsy, sociodemographic factors, socioeconomic status, prevalence, quality of life.

\section{Introduction}

Epilepsy is one of the most common chronic neurological disorders in the world, and the mean prevalence rate of active epilepsy was $8 \%$ worldwide [1-5]. A higher prevalence of epilepsy was estimated in developing countries (10-40) [6-8], as compared to developed countries (4.9\%)
Corresponding author: Dr. Seyed Shahabeddin Sadr Electrophysiology Research Center Neuroscience Institute Tehran University of Medical Sciences Tehran, Iran Phone: +98-2166521520 Fax: +98-2166521520 E-mail: sadr@tums.ac.ir 
[9]. Epilepsy prevalence might be associated with population demographics, sex, socioeconomic status and methodology of studies, with higher prevalence determined in males and people in the lower socioeconomic groups [9]. Furthermore, it is reported to be linked to poor academic achievement, low income and unemployment.

Many abnormalities of the nervous system can result in seizure activity such as brain tumors. Seizures can also occur in the normal nervous system when its metabolic balance is disturbed. The cause (etiology) of epilepsy may not be clearly known (idiopathic) or related to a particular disease state [10]. Schaller revealed that the pathophysiological modifications related to epileptic activity in peri- and intra-tumoral tissue are complex [11], and stated that the pathophysiological basis of seizures associated with brain tumors is related to different biochemical, anatomical and physiological changes [11].

Comprehensive information about epilepsy can help us in coping successfully with this situation by its management and epilepsy control. At present, epidemiologic data concerning the burden and etiology of epilepsy in different regions of Iran are scarce. Moreover, levels of suitable knowledge about epilepsy vary by country and are fewer in developing countries when compared with developed centuries because of the educational program. It was estimated that 4.7 million people suffer from epilepsy in nine countries of the Mediterranean region [12, 13]. Despite the benefits of control programs, they are not readily conduct in treatment centers due to a lack of consolidated reports in Iran. In this review, we systematically reviewed evidence-based determinants of health-related quality of life $(\mathrm{QOL})$, sociodemographic factors (age, sex, etc.), residential areas, general attitudes toward epilepsy, socioeconomic domains, prevalence and incidence in different people with epilepsy (PWE) living in Iran.

\section{Material and methods}

The Google search was performed principally and then the reference lists of relevant articles were searched in major electronic databases on patients with epilepsy including PubMed, ScienceDirect, Web of Science, Scopus, ISC, Iran Doc etc, and favoring publications with an English abstract, although a number of Persian sources were also included in this study. No restrictions were made pertaining to the time of available studies. The literature was chosen to reflect the study's focus on epilepsy: adolescents, children socioeconomic status, attitudes toward epilepsy, and the quality of life of patients with epilepsy. We screened the abstracts and full text of available articles. The following methodological data were considered for each relevant article: country of origin; study aim/ objective and study design. Then, eligible studies were chosen for inclusion. In addition, all modifications have been shown on the human epileptic brain in a schematic image (Figure 1).

\section{Results}

Prevalence and incidence of epilepsy in Iran

Previous studies on epilepsy were included in this review (Tables I and II). According to the Irani-

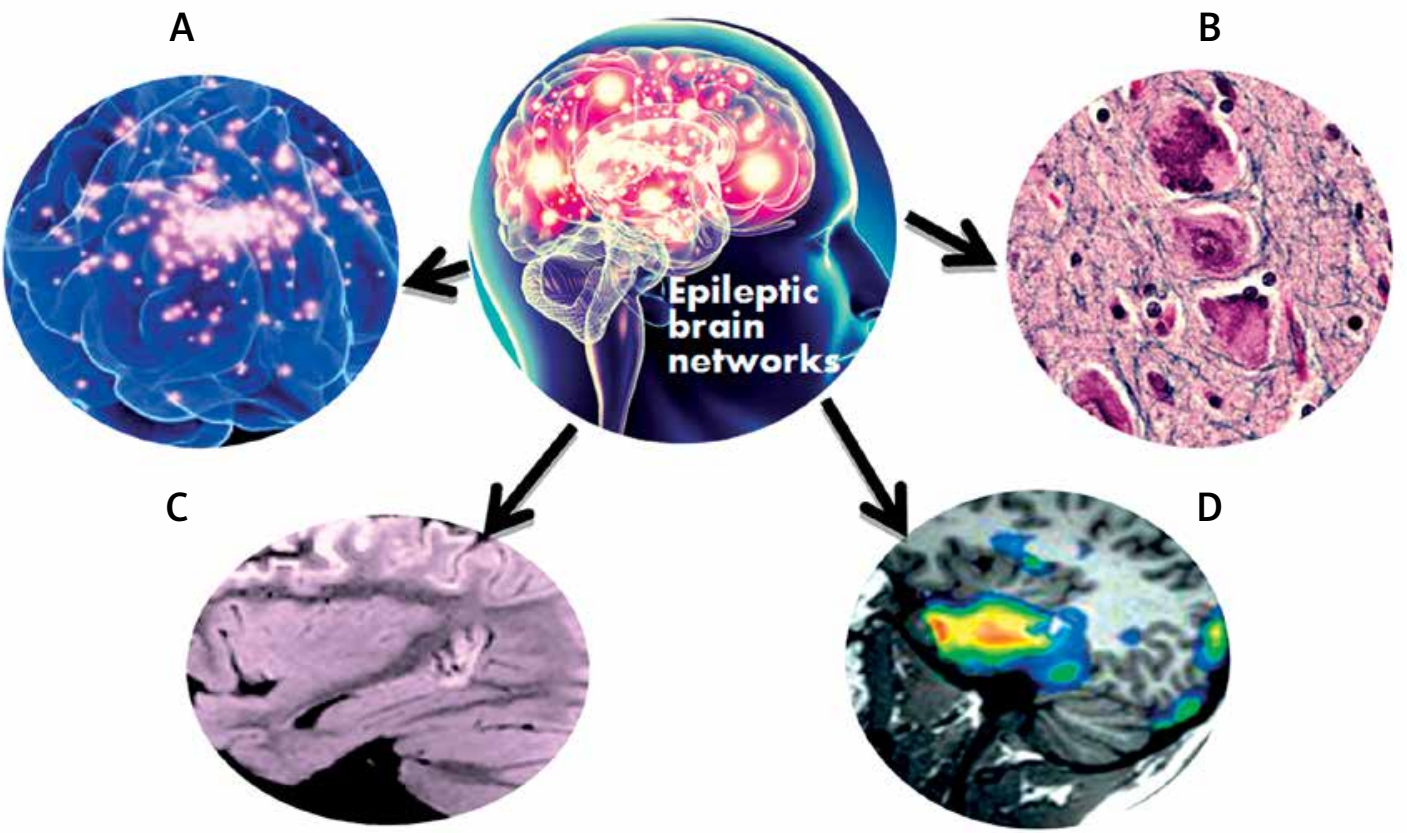

Figure 1. Graphic abstract: Schematic image shows the different types of brain changes (A-D) in epilepsy as a neurological disorder caused by unusual nerve cell activity in the brain 
Table I. Demographic characteristics and prevalence of epilepsy patients by sex and age group in different regions of Iran

\begin{tabular}{|c|c|c|}
\hline Demographic variable & Results & Reference \\
\hline Gender, mean \pm standard: & & Riasi et al., 2015 [55] \\
\hline Male & $27.44 \pm 6.57$ & \\
\hline Female & $27.93 \pm 7.76$ & \\
\hline \multicolumn{2}{|l|}{ Age group (M/F), $n$ (\%) [years]: } & \\
\hline $18-20$ & $43(24.0) / 65(33.3)$ & \\
\hline $21-30$ & $72(40.2) / 41(21.1)$ & \\
\hline $31-40$ & $64(35.8) / 89(45.6)$ & \\
\hline \multicolumn{2}{|l|}{ Age group, $n(\%)$ and SD of M/F [years]: } & Ebrahimi et al., 2012 [56] \\
\hline$\leq 9$ & $3(25.2)(17.66-27.74) / 3(29.7)(24.4-35.0)$ & \\
\hline $10-19$ & 2 (11.8) (9.7-13.9)/1 (5.6) (4.4-6.8) & \\
\hline $20-29$ & 0/4 (10.4) (6.6-14.1) & \\
\hline $30-39$ & $2(7.2)(5.1-9.3) / 0$ & \\
\hline $40-49$ & $2(14.5)(12.4-16.6) / 2(14.5)(12.4-16.6)$ & \\
\hline $50-59$ & $1(5.9)(5.5-6.3) / 0$ & \\
\hline $60-69$ & $1(6.7)(6.1-7.3) / 0$ & \\
\hline$\geq 70$ & $1(15.9)(10.7-21.1) / 1(12.8)(7.6-17.9)$ & \\
\hline Sex: & No $(\%)$ of $M / F$ & Talebi et al., 2013 [57] \\
\hline Male & $5(0 / 274)$ & \\
\hline Female & $3(0 / 131)$ & \\
\hline \multicolumn{2}{|l|}{ Age group, $n(\%)$ [years]: } & \\
\hline$\leq 9$ & 13.34 & \\
\hline $10-19$ & 18.05 & \\
\hline $20-29$ & 23.70 & \\
\hline $30-39$ & 16.33 & \\
\hline $40-49$ & 12.48 & \\
\hline $50-59$ & 7.74 & \\
\hline $60-69$ & 4.47 & \\
\hline $70-79$ & 2.91 & \\
\hline$\geq 80$ & 0.98 & \\
\hline \multicolumn{2}{|l|}{ Gender, $n(\%)$ : } & Zibaei et al., 2011 [58] \\
\hline Male & $55(64.7)$ & \\
\hline Female & $30(35.3)$ & \\
\hline \multicolumn{2}{|l|}{ Age group, $n(\%)$ [years]: } & \\
\hline $1-19$ & $42(49.4)$ & \\
\hline $20-39$ & $28(32.9)$ & \\
\hline $40-59$ & $12(14.1)$ & \\
\hline$\geq 60$ & $3(3.5)$ & \\
\hline
\end{tabular}


Table I. Cont.

\begin{tabular}{|c|c|c|}
\hline Demographic variable & Results & Reference \\
\hline \multicolumn{2}{|l|}{ Gender, $n$ (\%) [years]: } & \multirow{4}{*}{$\begin{array}{c}\text { Asadi-Pooya et al., } 2012 \\
\text { [59] }\end{array}$} \\
\hline Male & $142(53.8)$ & \\
\hline Female & $122(46.2)$ & \\
\hline Age, mean \pm SD [years] & $28.7 \pm 10.5$ & \\
\hline \multicolumn{2}{|l|}{ Gender, $n$ (\%) [years]: } & \multirow{13}{*}{$\begin{array}{c}\text { Rezaei and Saeidi, } 2000 \\
{[60]}\end{array}$} \\
\hline Male & $177(61)$ & \\
\hline Female & $113(39)$ & \\
\hline \multicolumn{2}{|l|}{ Age group, $n(\%)$ [years]: } & \\
\hline $0-2$ & $14(4.8)$ & \\
\hline $2-10$ & $80(27.6)$ & \\
\hline $11-20$ & $94(32.4)$ & \\
\hline $21-30$ & $44(15.2)$ & \\
\hline $31-40$ & $34(11.7)$ & \\
\hline $41-50$ & $6(2.1)$ & \\
\hline $51-60$ & $9(3.1)$ & \\
\hline $61-70$ & $3(1)$ & \\
\hline $71-80$ & $6(2.1)$ & \\
\hline
\end{tabular}

M-male, F-female.

Table II. Classification on the prevalence of epileptic patients in various regions of Iran

\begin{tabular}{|lccc|}
\hline Study location (city) & Study period & No. of patients & Prevalence (\%) per 1000 persons \\
\hline Tehran & 2002 & 4361 & 105.6 \\
\hline Tehran & 2005 & 50 & 50 \\
\hline Tehran & 2005 & 113 & 70 \\
\hline Tehran & 2006 & 454 & 18 \\
\hline Qom & 1998 to 2007 & 466 & 31 \\
\hline Khorasan & 2008 & 369 & 81 \\
\hline Esfahan & 2010 & 101 & 59 \\
\hline Birjand & 2010 & 2085 & 57 \\
\hline Yazd & 2010 & 40 & 10 \\
\hline Mazandaran & 2010 & 150 & 51.2 \\
\hline Kermanshah & 1994 to 2010 & 391 & 7.87 \\
\hline Kerman & 2010 to 2011 & 23 & 20.2 \\
\hline Shiraz & 2008 to 2011 & 2190 & 8.7 \\
\hline Shiraz & 2008 to 2013 & 239 & 5 \\
\hline
\end{tabular}

an Epilepsy Association, about 80,000 epileptic patients registered in Iran until the end of 2007. The point prevalence of epilepsy has been estimated to be between 2.1 and 4 per 1000 individuals in Iran [14]. A previous study indicated that prevalence of epilepsy increased from 2 to 34 per 10000 individuals during the period of 1970 to 2000 in mentally retarded students, Tehran. Moreover, the prevalence of epilepsy in the study population was calculated a $10.55 \%$ among the retarded children in 2002 [15]. 
Noorbala et al. [16] reported that epilepsy prevalence was $1.2 \%$ (crude prevalence per 1000 population) in 2004 in Iran.

A cross-sectional nationwide epidemiological study of the Iranian population was conducted by Mohammadi et al. [17] in 2001. They estimated that the prevalence of epilepsy was $1.8 \%$. The prevalence of seizures was about $0.95 \%$ in primary school children in Tabriz (9/56 per 1000 individuals) [18], and the prevalence of epilepsy was estimated as about $0.9 \%$ at primary schools of Birjand, South Khorasan Province, in 2010.

Furthermore, considering the existing data, it has been estimated that the pooled prevalence of epilepsy is about $5 \%$ in Iran, $5 \%$ in central Iran, $1 \%$ in northern parts and $4 \%$ in eastern Iran [19], while its prevalence and incidence in different regions of Iran were given uncertain status awaiting further data. It is believed that further epidemiologic data are required for interpretation of the disease status, and the prevalence and incidence of epilepsy in Iran are now difficult to interpret without comprehensive epidemiological data. There is no available information to estimate the incidence of epilepsy in Iran.

\section{Factors associated with incidence and prevalence}

\section{Age}

Age-specific incidence of epilepsy has been indicated to be higher in young children and the elderly, while its incidence rate is lower in young and middle-aged adults (Table I). Although current studies are not in perfect concordance, it has been reported that epilepsy increases in older age (over 65 years of age) and among people of Asian descent [15].

In developed countries, most previous investigations reported that the prevalence of epilepsy increased with age after 50 [20, 21]. A meta-analysis study estimated that the epilepsy recurrence rate based on age was 0.05 in people under 20 years and 0.04 in those over 20 years of age [19]. There is a general trend towards high prevalence of epilepsy among people in adolescence or early adulthood groups [21, 22]. Some studies have reported higher rates of epilepsy for people under 20 years old in Iran [22-24], while other studies found higher rates of disease in people aged over 20 years $[17,18,25,26]$.

\section{Gender}

Males have a slightly higher risk as of developing epilepsy as compared to females [27, 28]. However, the overall difference is negligible. A meta-analysis and systematic review reported that prevalence of epilepsy did not show a signif- icant gender difference in Iran $[19,29]$. Moreover, a similar pattern was seen in Pakistan and India [29]. However, another investigation reported that epilepsy was more common in females as compared to males [17]. The prevalence of epilepsy based on gender in southern Iran is not markedly different from the worldwide figure [30]. Despite the narrowing of gender differentials in the world, the prevalence and incidence of epilepsy require further investigations in Iran and cannot be interpreted with certainty without epidemiological studies (Table I).

\section{Residential areas}

A cross-sectional nationwide epidemiological study indicated that the prevalence of epilepsy was not markedly correlated with the residential areas [17]. It cannot be interpreted whether residential areas are associated with high prevalence of epilepsy in Iran, due to limited information. However, the lack of facilities and limited services in rural areas may be influential in this matter.

\section{Socioeconomic status}

Socioeconomic factors such as infections, poor hygiene, and poor health-seeking behavior and poor nutrition increase the risk of epilepsy and its outcome. There have been few relevant studies in Iran. The prevalence of epilepsy appears to be associated with socioeconomic status in the lower socioeconomic groups [12]. Among the few investigations, socioeconomic factors were rarely evaluated for such correlations in Iran. An epidemiological study of the Iranian population conducted by Mohammadi et al. [17] indicated that occupational status may be related to epilepsy in males. They suggested that unemployed, the most common occupation status, was correlated with the disease, in agreement with previous studies worldwide [31-33]. In contrast to previous studies, epilepsy was found to be linked to poor academic level [26, 34, 35].

Mohammadi et al. [17] reported that epilepsy was more common at a higher educational level compared with the lower ones. On the other hand, statistically significant associations were reported between epilepsy and psychological needs, gender, employment status, education level, marital status and number of family members [36]. A previous study in Iran indicated that marital status was not correlated with epilepsy, while some prior studies have found a lower rate of marriage in patients with epilepsy worldwide [32]. Moreover, it has been shown that marital status and number of children had no effect on quality of life, while educational level, occupation and income did in- 
fluence quality of life [37]. Worldwide, it has been shown that low socioeconomic status, low income, and less education are associated with epilepsy, and these factors have effects on hospitalization, drug-related side effects, and uncontrolled seizures [34, 35].

\section{General attitudes toward epilepsy in Iran}

In a comprehensive study, Masoudnia [38] evaluated Iranian awareness, understanding and attitudes towards epilepsy among five major Iranian ethnic groups, i.e. Persian, Azeri, Kurd, Lur, and Arab. He found that the level of awareness about epilepsy was acceptable. Moreover, most of them believed physical causes of epilepsy and rejected metaphysical causes. Iranian people had a positive attitude about their child's employment and childbearing, but their attitude regarding children's marriage with a person with epilepsy were highly negative, while attitudes about the treatment of epilepsy were desirable.

Ghanean et al. [39] suggested that the awareness and attitudes towards epilepsy are more or less similar to those in Europe, but their attitudes regarding children's marriage with epilepsy patients were much lower. Another study in western Iran reported that there is acceptable awareness and positive attitudes about epilepsy among schoolteachers [40]. Another study in Fars province of Iran reported that more than two-thirds of the biology teachers had a positive attitude to epilepsy, while the remainder had misconceptions and negative attitudes toward epilepsy [41]. The perception of epilepsy seems to be relatively good, because modern treatment has considerably decreased its medical and social consequences.

\section{Quality of life (QOL) of epileptic patients}

Epilepsy influences QOL in patients and epileptic patients have lower QOL compared with that in patients with other chronic diseases and normal people [42-44]. As previously shown in the literature, psychological and social issues are linked to epilepsy including self-image, socioeconomic status, insurance issues, and stigma. However, epilepsy has an important role for the patient, family, and society. Management of seizures and lifestyle have key roles for epilepsy therapy. Age, duration of the disease, and frequency and severity of seizures are negatively correlated with QOL. Moreover, type of epilepsy is associated with the opinion of people about their QOL.

In patients with epilepsy, self-management can help individuals to improve seizure control and well-being [45]. Various training programs have been conducted regarding epileptic patients in Iran. Training programs for patients and parents of epileptic children are markedly effective for self-management [46]. Current evidence indicates their direct association with patient satisfaction and self-management [47]. Various studies have evaluated the QOL of epileptic patients worldwide. In a comprehensive study in Iran and Persian Gulf countries, differences were found in the QOL compared with participants in Europe. Moreover, they indicated that epileptic patients had low quality of life in aspects including physical, social and energy [48]. Darabi et al., in a cross-sectional study, found that seizure frequency and education are markedly associated with QOL in patients with epilepsy. They concluded that reducing seizure frequency and identification of intervening factors with education are required for improvement of QOL in patients with epilepsy [49].

Javaheri et al. in Iran showed the effectiveness of cognitive-behavioral stress management (CBSM) group education for QOL in females with temporal lobe epilepsy. They suggested that improving patients' physical, mental, and social conditions is correlated with quality of life in patients [50]. Aliasgharpour et al. in 2013 suggested that the educational program is beneficially effective for self-management behaviors in patients with epilepsy in Zanjan province, Iran. This indicates that an educational program must become an important service in epilepsy care [51].

It has been shown that incidence of epilepsy was high in childhood and adolescence and formation of personality can be developed in this period. Adolescents with epilepsy, with comorbid conditions, had lower QOL $[52,53]$. Another study in Iran showed an unsatisfactory state of the QOL of adolescents with epilepsy as compared to other studies. This study suggested serious concern regarding the psychological status and risk factors for the QOL of adolescents with epilepsy in Iran. It was found that stigma in adolescents with epilepsy was higher compared with that in other countries, and QOL was lower in the patients. It has been reported that adolescents with epilepsy on monotherapy have better QOL [54]. Rajabi et al. reported that good effects of antiepileptic drugs were correlated with the QOL of those on polytherapy [37]. Successful self-management of chronic diseases requires appropriate educational support for effective self-management. Self-management training programs can be used for improving the skills and self-sufficiency, and patients should be informed on management and treatment of epilepsy. Demographic characteristics, socio-economic factors and clinical presentation are linked to different QOL of these patients among nations. Self-management training programs must be based on the learners' specific characteristics including sex, age, culture, educational level, residential place, etc. [47, 55-60]. 
In conclusion, the point prevalence of epilepsy has been estimated to be between 2.1 and 4 per 1000 individuals in Iran. The overall prevalence of epilepsy in Iran was calculated to be about 5\% [19]. The prevalence of epilepsy appears to be correlated with socioeconomic status in the lower socioeconomic groups. A statistically significant association has been found between epilepsy and psychological needs, gender, employment status, education level, marital status and number of family members. It has been suggested that the awareness and attitudes towards epilepsy and treatment are acceptable, but attitudes regarding children's marriage with epileptic patients were much lower. The psychological and social issues are linked to epilepsy including self-image, socioeconomic status, insurance issues, and stigma. In patients with epilepsy, self-management can help individuals to improve seizure control and well-being. Epileptic patients had low quality of life in aspects including physical, social and energy.

Demographic characteristics, socio-economic factors and clinical presentation are linked to different QOL of these patients among nations. The educational program is beneficially effective for self-management behaviors in patients with epilepsy. Self-management training programs can be used for improving the skills and self-sufficiency, and patients should be informed on management and treatment of epilepsy. However, better data sources, a good recording system, and new techniques are needed to identify epidemiology of epilepsy. Available data are limited to published investigations in Iran. Other non-published data and comprehensive studies are required for better evaluation of the situation of epilepsy in Iran.

\section{Conflict of interest}

The authors declare no conflict of interest.

\section{References}

1. Bell GS, Sander JW. The epidemiology of epilepsy: the size of the problem. Seizure 2001; 10: 306-14.

2. Ngugi AK, Bottomley C, Kleinschmidt I, Wagner RG, Kakooza-Mwesige A, Ae-Ngibise K. Prevalence of active convulsive epilepsy in subSaharan Africa and associated risk factors: cross-sectional and case-control studies. Lancet Neurol 2013; 4422: 1-11.

3. Murray CJ, Vos T, Lozano R, et al. Disability adjusted life years (DALYs) for 291 diseases and injuries in 21 regions, 1990-2010: a systematic analysis for the Global Burden of Disease Study 2010. Lancet 2012; 380: 2197-223

4. World Health Organization. Epilepsy: epidemiology, aetiology and prognosis. Fact Sheet No. 165. WHO, Geneva.2001.

5. Belhocine M, de Boer H, Mandlhate C (eds.). Epilepsy in the WHO African Region: bridging the gap. World Health Organization, Geneva 2004.
6. Debrock C, Preux PM, Houinato D, Druet-Cabanac M, Kassa F, Adjien C. Estimation of the prevalence of epilepsy in the Benin region of Zinvie using the capture-recapture method. Int J Epidemiol 2000; 29: 330-5.

7. De Bittencourt PR, Adamolekum B, Bharucha N, et al. Epilepsy in the tropics: I. Epidemiology socioeconomic risk factors, and etiology. Epilepsia 1996; 37: 1121-7.

8. Preux PM, Druet-Cabanac M. Epidemiology and aetiology of epilepsy in sub-Saharan Africa. Lancet Neurol 2005; 4: 21-31.

9. Ngugi AK, Bottomley C, Kleinschmidt I, Sander JW, Newton CR. Estimation of the burden of active and life-time epilepsy: a meta-analytic approach. Epilepsia 2010; 51: 883-90.

10. Dayan PS, Lillis K, Bennett J, et al. Prevalence of and risk factors for intracranial abnormalities in unprovoked seizures. Pediatrics 2015; 136: e351-60.

11. Schaller B. Influences of brain tumor-associated $\mathrm{pH}$ changes and hypoxia on epileptogenesis. Acta Neurol Scand 2005; 111: 75-83.

12. Morgan CL, Ahmed Z, Kerr MP. Social deprivation and prevalence of epilepsy and associated health usage. J Neurol Neurosurg Psychiatry 2000; 69: 13-7.

13. Rodin E, Rennick P, Dennerll R, Lin Y. Vocational and educational problems of epileptic patients. Epilepsia 1972; 13: 149-60.

14. Darabi F. Assessment to results of integrated mental health program in primary health care system Chaharmahal Bakhtiari. Thesis in Master of Nursing, ShareKord University of Medical Sciences 2003; 24-6.

15. Nachvak M, Haghighat HR, Rezaei M. Prevalence and monitoring of retarded childs in Tehran at 2002. Quarterly of Science-Research Journal of Kermanshah University of Medical Sciences 2004; 3: 34-42.

16. Noorbala AA, Bagheri Yazdi SA, Yasamy MT, Mohammad K. Mental health survey of the adult 21. Population in Iran. Br J Psychiatry 2004; 184: 70-3.

17. Mohammadi M, Ghanizadeh A, Davidian H, Mohammadi M, Norouzian M. Prevalence of epilepsy and co morbidity of psychiatric disorders in Iran. Seizure 2006; 15: 476-82.

18. Pashapour A, Sadrodini A. Grandmal epilepsy and EEG variations in primary school children at Tabriz. Medical Journal of Tabriz University of Medical Sciences 2001; 50: 23-7.

19. Sayehmiri K, Tavan H, Sayehmiri F, Mohammadi I, Carson K. Prevalence of epilepsy in Iran: a meta-analysis and systematic review. Iran J Child Neurol 2014; 8: 9-17.

20. Forsgren, L. Prevalence of epilepsy in adults in northern Sweden. Epilepsia 1992; 33: 450-8.

21. Olafsson E, Hauser WA. Prevalence of epilepsy in rural Iceland: a population-based study. Epilepsia 1999; 40: 1529-34.

22. Birbeck GL, Kalichi EM. Epilepsy prevalence in rural Zambia: a door-to-door survey. Trop Med Int Health 2004; 9: $92-5$.

23. Najafi MR, Rezaei F, Vakili Zarch N, Dehghani F, Barakatein M. Survey of pattern of personality and psychopathology in patients with Grandmal and complex partial epilepsy and comparison with control group. Journal of Shaheed Sadoughi University of Medical Sciences 2010; 2: 84-91.

24. Etemadifar M, Mirabdolbaghe P. Demographic and clinical characteristics of young epilepsy mortalities in Isfahan. Two quarterly of South Pediatric, Persian Golf Center of Health Researches in Boushehr University of Medical Sciences 2004; 2: 160-4. 
25. Nasehi MM, Mahvalati Shamsabadi F, Ghofrani M. Associated factors in response to treatment in children with refractory epilepsy. J Babol University Med Sci 2010; 12: 61-6.

26. Kaheni S, Riyasi HR, Rezvani Kharashad MR, Sharifzadeh $\mathrm{GH}$, Nakhaei S. Prevalence of epilepsy in children at primary schools and awareness of teachers about epilepsy at primary schools of Birjand at 2010. Novel Cares 2011; 3: $135-42$.

27. Newton CR. Epilepsy in poor regions of the world. Lancet 2012; 380: 1193-201.

28. Wilden JA, Cohen-Gadol AA. Evaluation of first nonfebrile seizures. Am Fam Phys 2012; 86: 334-40.

29. Shakirullah NA, Muhammad Nabi AKH. The prevalence, incidence and etiology of epilepsy. Int J Clin Exp Neurol 2014; 2: 29-39.

30. Inaloo S, Katibeh P. An epidemiologic study of 389 children with epilepsy in southern Iran. Iran J Child Neurol 2011; 5: 15-20.

31. Lisle JR, Waldron HA. Employees with epilepsy in the NHS. Br Med J 1986; 292: 305-6.

32. Callanghan N, Crowley M, Goggin T. Epilepsy and employment, marital, education and social status. Ir Med J 1992; 85: 17-9.

33. Hart YM, Shorvon SD. The nature of epilepsy in the general population. I. Characteristics of patients receiving medication for epilepsy. Epilepsy Res 1995; 21: 43-9.

34. Li X, Sundquist, J, Sundquist K. Socioeconomic and occupational risk factors for epilepsy: a nationwide epidemiological study in Sweden. Seizure 2008; 17: 254-60.

35. Begley C, Basu R, Lairson D, Reynolds T, Dubinsky S, Newmark M. Socioeconomic status, health care use, and outcomes: persistence of disparities over time: disparities in epilepsy care and outcomes. Epilepsia 2011; 52: 957-64.

36. The relationship between the needs of patients with epilepsy and their quality of life in Society member's patients in Iran. MSc thesis, Ministry of Health and Medical Education - Iran University of Medical Sciences and Health Services 1999.

37. Rajabi F, Dabiran S, Hatmi ZN, Zamani GR. Quality of life of epileptic patients compared to general population in Tehran. Acta Med Iran 2009; 47: 75-8.

38. Masoudnia E. Awareness, understanding and attitudes towards epilepsy among Iranian ethnic groups. Seizure 2009; 18: 369-73.

39. Ghanean H, Nojomi M, Jacobsson L. Public awareness and attitudes towards epilepsy in Tehran, Iran. Global Health Action 2013; 6: 21618.

40. Karimi N, Heidari M. Knowledge and attitudes toward epilepsy among school teachers in West of Iran. Iran J Neurol 2015; 14: 130-5.

41. Asadi-Pooya AA, Torabi-Nami M. Knowledge and attitude towards epilepsy among biology teachers in Fars Province, Iran. Iran J Child Neurol 2012; 6: 13-8.

42. Stavem K, Loge JH, Kaasa S. Health status of people with epilepsy compared with a general reference population. Epilepsia 2000; 41: 85-90.

43. Santhouse J, Carrier C, Arya S, Fowler H, Duncan S A comparison of self-reported quality of life between patients with epilepsy and neurocardiogenic syncope. Epilepsia 2007; 48: 1019-22.

44. Berto P. Quality of life in patients with epilepsy and impact of treatments. Pharmacoeconomics 2002; 15: 1039-59.

45. Austin JK, Boer H. Disruption in social functioning and services facilitating adjustment for the child and adult with epilepsy. In: Epilepsy: a comprehensive textbook. Engel J, Pedley T (eds.). Lippincott-Raven, Philadelphia 1997; 2191-201.

46. Wohlrab GC, Rinnert S, Bettendorf U, Fischbach H, Heinen G. Famoses: a modular educational program for children with epilepsy and their parents. Epilepsy Behav 2007; 1: 44-8.

47. Yadegary MA, Maemodan FG, Nayeri ND, Ghanjekhanlo $A$. The effect of self-management training on health-related quality of life in patients with epilepsy. Epilepsy Behav 2015; 50: 108-12.

48. Baker GA, Jacoby A, Gorry J, Doughty J, Ellina V. Quality of life of people with epilepsy in Iran, the Gulf, and Near East. SIGN Group. Epilepsia 2005; 46: 132-40.

49. Darabi L, Montazeri A, Ebrahimi F, Vahdaninia M, Togha M. Clinical and demographic characteristics and quality of life in patients with epilepsy. Payesh J 2010; 9: 215-21.

50. Javaheri R, Neshat-Doost HT, Molavi H, Zare M. Efficacy of cognitive-behavioral stress management therapy on improving the quality of life in females with temporal lobe epilepsy. Arak Med Univ J 2010; 3: 32-43.

51. Aliasgharpour M, Dehgahn Nayeri N, Yadegary $M$, Haghani $H$. Effects of an educational program on selfmanagement in patients with epilepsy. Seizure 2013; 22: $48-52$

52. Taylor J, Jacoby A, Baker GA, Marson AG. Self-reported and parent-reported quality of life of children and adolescents with new-onset epilepsy. Epilepsia 2011; 52: 1489-98.

53. Wu DY, Ding D, Wang Y, Hong Z. Quality of life and related factors in Chinese adolescents with active epilepsy. Epilepsy Res 2010; 90: 16-20.

54. Barbosa FD, Guerreiro MM, De Souza EA. The Brazilian version of the quality of life in epilepsy inventory for adolescents: translation, validity, and reliability. Epilepsy Behav 2008; 13: 218-22.

55. Riasi H, Rajabpour Sanati A, Ghaemi K. The stigma of epilepsy and its effects on marital status. Springerplus 2015; 3: 762.

56. Ebrahimi HA, Shafa MA, Hakimzadeh Asl S. Prevalence of active epilepsy in Kerman, Iran: a house based survey. Acta Neurol Taiwan 2012; 21: 115-24.

57. Talebi M, Farhoudi M, Godszad S, Abdollahi H, Talebi M, Aghili AR. Epidemiological study about the prevalence of the types of epilepsy in Tabriz city. Medical Journal of Tabriz University of Medical Sciences and Health Services 2014; 36: 60-5.

58. Zibaei M, Zinab Zamani Z, Chahichi Esfahani A, Anbari KH, Nazer MR. Toxoplasma infection and epilepsy: a case-control study in Iran. Neurol Asia 2011; 16: 299302.

59. Asadi-Pooya AA, Nikseresht A, Yaghoubi E, Nei M. Physical injuries in patients with epilepsy and their associated risk factors. Seizure 2012; 21: 165-8.

60. Rezaei AA, Saeidi SH. The study of age and sex frequency of epilepsy and its relating factors in epileptic patients referred to Sina and Ghaem Hospital in Hamadan city, 1986-95. J Rehabil 2000; 1: 52-6. 